\title{
The role of psychological factors in predicting latrine ownership and consistent latrine use in rural Ethiopia: a cross- sectional study
}

Fikralem Alemu ${ }^{1 *}$, Abera Kumie ${ }^{2}$, Girmay Medhin ${ }^{3}$ and Janvier Gasana ${ }^{4}$

\begin{abstract}
Background: Inadequate sanitation is one of the leading causes of disease in poor and middle-income countries. Objective: The objective of the study was to identify the psychological factors that predict latrine ownership and consistent latrine use in the rural Becho district of central Ethiopia.

Method: A quantitative, cross-sectional, community based study was conducted. A total of 1047 heads of household were interviewed using a structured questionnaire. Ownership of latrine and consistent latrine use constituted the outcome variable of the study. Data were entered using Epi Info version 3.5.4 and were analyzed using SPSS version 20.
\end{abstract}

Results: Of the 1047 households, $73 \%$ owned a traditional pit latrine. Among the psychological factors, attitude (AOR 1.70; 95\% Cl 1.21-2.37) and injunctive norm (AOR 6.18; 95\% Cl 4.46-10.44) were positively and significantly associated with latrine ownership. Among the demographic factors, having a family size of more than six ( $A O R=1$. 43; 95\% Cl 1.01-1.97, having a child attending school ( $\mathrm{AOR}=1.88$; 95\% $\mathrm{Cl}$ 1.17-3.02), and having a high school education ( $A O R=1.98 ; 95 \% \mathrm{Cl} 1.34-2.87$ ) were significantly associated with latrine ownership. With respect to exposure to communication about sanitation (the cues to action), households that had a family member who took part in Community Led Total Sanitation and Hygiene (CLTSH) triggering were three times more likely to be latrine owners than those who did not participate in CLTSH triggering (95\% Cl 1.92-4.78.) Results from adjusted logistic regression analysis of potential predictors of consistent latrine use showed that having a positive attitude (AOR 7.00; 95\% Cl 4.55-10.55), owning of a latrine that had superstructure (AOR $2.395 \% \mathrm{Cl} 1.47-3.48$ ), having a clean latrine (AOR 1.69 95\% Cl 1.00-3.00), and having a latrine with a protected door (AOR 1.94; 95\% Cl 1.10-3.48) were significantly associated with consistent latrine use.

Conclusion: The study findings showed that attitude and injunctive norm are the psychological predictors of latrine ownership, and consistent latrine use was associated with attitude, cleanliness of the latrine, and its privacy. Hence, sanitation intervention needs to focus on changing societal norms, attitudes, and the promotion of latrine quality.

Keywords: Latrine ownership, Consistent latrine use, Rural, Ethiopia, Psychological factors

\footnotetext{
* Correspondence: fikeralemme@yahoo.com

${ }^{1}$ Ethiopian Institute of Water Resources, Water and Health Program, Addis

Ababa University, Addis Ababa, Ethiopia

Full list of author information is available at the end of the article
} 


\section{Background}

Improvement in sanitation has a profound effect on human health (1-6). Evidence suggests that improved sanitation reduces diarrheal disease by up to $36 \%$ and intestinal parasitic infection by up to $50 \%$ [1-5]. However, in 2015, an estimated 2.4 billion people still lacked access to improved facilities [6]. More than 1.8 million deaths occur globally each year as the result of diarrheal disease, and children under age 5 accounted for $90 \%$ of those deaths [7-9].

Ethiopia has a high level of diseases due to poor sanitation $[5,10]$. Diarrhea is the second-leading cause of death in children under age five [11]. More than 26 million Ethiopians are infected with intestinal parasites [12], and approximately $38 \%$ of children under age five are stunted [13]. Every year, an estimated 64,540 child deaths occur in Ethiopia due to inadequate water, sanitation, and hygiene [14]. Ethiopia launched a health extension program a decade ago. Health extension workers provide door-to-door health education to the households $[15,16]$. In 2011, Ethiopia adopted the Community Lead Total Sanitation and Hygiene (CLTSH) programs as a national sanitation strategy [17]. Although these programs have been successful in decreasing open defecation [18], there was no progress in access to improved sanitation in Ethiopia, increasing from a baseline of $3 \%$ in 1990 to $28 \%$ in 2017 [6].

Lessons learned from the implementation of sanitation programs in Sub-Saharan Africa and elsewhere during the past two decades show that programs that provide or subsidize a toilet without addressing behavioral changes result in unused sanitation facilities, and the facilities themselves are often not maintained [19-22]. An increasing body of literature suggests that the effectiveness of sanitation depends not only on the provision of sanitation facilities but also, and most importantly, on the compliance of individuals [23-25]. Models of behavioral change suggest that behavioral change interventions should be planned based on the identified factors of the targets [26]. Although there is growing interest and focus on sanitation behavior by program planners and practitioners, there are relatively few studies on sanitation behavior that can inform the design of successful programs and strategies [27]. Limited studies applied theoretical models and frameworks to understand factors that determine the adoption and consistent use of sanitation facilities in developing countries [28]. However, most behavioral change programs on sanitation focus on educating people about risks of diseases and infections without sufficient grounding in behavioral theory [22].

The Risk, Attitude, Norm, Ability, Self-regulation (RANAS) model underlines the importance of psychological factors in predicting Water, Hygiene and Sanitation (WASH) behaviors. The model proposes specific intervention strategies for specific factors [27]. Here, we present a study guided by the RANAS model to investigate the individual psychological predictors of latrine adoption in the rural Becho district of Ethiopia. The Becho district was purposely selected because sustaining latrine adoption has been a challenge in the area [29]. The study answers the following research question: What are the psychological determinants of latrine ownership and consistent latrine use in the rural Becho district of Ethiopia?

\section{Methods \\ Study design}

A community-based cross-sectional quantitative study was employed

\section{Study area and study population}

Ethiopia has nine regional states and two city administrations. Each region is subdivided into a set of zones, and each zone is divided into woreda (equivalent to a district). A kebele is the lowest-level administrative structure. This study was conducted in the Oromia region, a rural kebele of the Becho woreda from May 1 to May 30, 2015. Becho is located $80 \mathrm{~km}$ from Addis Ababa, the capital city of Ethiopia. Based on the 2007 national demographic census, the district had a projected total population of 88,550 in $2015,80.4 \%$ of which were rural residents [30]. According to the 2014 woreda health report, the percentage of the population owning any kind of latrine in the Becho district was 57\% [29].

\section{Study participants}

Study participants included heads of household who had been residents of the Becho district for at least six months prior to the study period. Those temporarily staying in the study area for different purposes, such as caring for the household, were excluded from the study.

\section{Sample size and sampling procedure}

A sample size of 1146 was estimated using the software Epi Info Version 3.5.4 (Centers for Disease Control and Prevention, Atlanta, GA, USA), considering 68\% latrine coverage (i.e., any kind of latrine) from Ethiopia's 2014 mini DHS report [31]; the design effect was 2, the margin of error was 0.04 , and the confidence level was $95 \%$. The Becho district has a total of 19 kebeles, and 17 are rural. We implemented a two-stage sampling technique. First, we selected eight rural kebeles (clusters) using simple random sampling, and then study participants from each kebele were selected using a systematic random sampling method. Using a sampling interval of six, the first household in each kebele was selected by simple random sampling, and then data collectors enrolled every sixth household to participate in the study. 


\section{Data collection method and procedure}

Data were collected using a structured questionnaire that was originally prepared in English and then translated into the local language (Oromiffa). The questionnaire was pretested among 50 households residing in a non-sampled cluster district, and the modified questionnaire was used in the final survey. We assessed the challenges of social desirability during pretesting, and some of the language in the questionnaire was modified. In addition, the data collectors were recruited from the study area to minimize the unknown urban person effect. Three supervisors with a master's degree and ten data collectors with at least a diploma-level education who speak the local language were recruited to administer the survey. Training was provided to data collectors and supervisors over three days. During the data collection, the first author and supervisors closely examined the data collectors administering the interview. All completed questionnaires were checked by the supervisors in the field for missing values, skip patterns, and logic. Corrections for possible inconsistencies were made in the field. For incomplete data, the respondents were revisited the next day. Supervisors randomly selected 25\% of the completed questionnaires from each data collector and rechecked by visiting the households.

\section{Variables and measurements}

\section{Outcome variable}

Latrine ownership and consistent latrine use were the outcome variables for investigating the predicting factors. Latrine ownership was measured by asking the participants if they own any kind of latrine, which was confirmed through observation. The frequency of latrine use over the last week by latrine owners was assessed using a 4-point Likert scale of 'always,' 'very often', 'less often', and 'never'. Respondents who reported always using a latrine were categorized as consistent latrine users, and the rest were categorized as inconsistent latrine users.

\section{Predictor variables}

Psychological factors, demographic factors, and cues to action were investigated as predictors of latrine ownership and consistent latrine use. The items in the questionnaire that assessed psychological factors are displayed in Table 1. Psychological factors included perceived risk (perceived vulnerability and perceived severity), attitude, and perceived norm (both injunctive and descriptive norms) [27]. We assessed the influence of latrine quality on consistent latrine use, which included cleanliness and having a superstructure or door that could provide privacy [32]. Questions for the psychological variable were adopted from prior studies that examined psychological predictor of a specific behavior
[33-35], and RANAS model [36, 37] and we contextualized it for latrine ownership and consistent latrine use. Overall, the questions used to measure psychological variables were developed using the theory of planned behavior (TPB)/theory of reasoned action (TRA) [38, 39] and the Health Belief Model (HBM) [32]. These theories have been widely used in the context of sanitation and hygiene behavior [38, 39]. The participants' intention to build a latrine and their self-efficacy were also measured and reported.

Risk perception As described by the Health Belief Mode (HBM), we measured perceived vulnerability, which is the extent to which the person believes that she/he is susceptible to diarrheal disease due to contamination from open defecation; and perceived severity, which is the perception of the severity of the illness consequences [32]. A Likert scale (1-5) was adopted to measure perceived vulnerability and perceived severity. Responses of 1-3 were recorded as low vulnerability and severity, whereas a response of 4 or 5 was recorded as high vulnerability or severity.

Norm perception: The effects of social norm perception on a particular behavior is described by the theory of normative social behavior (TNSB) [40], which is analogous to the subjective norm in the theory of reasoned action (TRA) [38]. Social norm is differentiated as the descriptive norm - an individual's perception about how others behave-and an injunctive norm, which is the perception about how others expect them to behave [41, 42]. In this study, the descriptive norm for latrine use is defined as the participant's perception about the prevalence of latrine use. It was measured using 3 items that were adopted from studies on social norms [43]. The composite score, ranging from 4 to 15 , was then recorded with high descriptive norm latrine use being a score greater than 10.6, and low descriptive norm for a score less than or equal to 10.5 . The injunctive norm is the participant's perception that important referents expect them to behave. The injunctive norm for latrine ownership was measured using two items. The composite score, ranging from 2 to 10 , was recorded as high injunctive norm latrine ownership for a score of 8 to 10, and low injunctive norm form latrine ownership for a score of 2 to 7 . The injunctive norm for consistent latrine use was measured using 3 items. The total score of three items ranged from 3 to 15, which was recorded as high and low for scores of 3 to 10 and scores greater than 10 , respectively.

Attitude: The TRA/TPB explains that attitude, a feeling arising when performing or thinking about a behavior, predicts a certain behavior $[39,44]$. We assessed attitude 
Table 1 Summary of measurements used to assess the psychological predictors of latrine ownership and consistent latrine use

\begin{tabular}{|c|c|c|c|}
\hline Factor & Items & Responses & values \\
\hline \multicolumn{4}{|l|}{ Outcome variables } \\
\hline Latrine ownership & Ownership of latrine & No/Yes for ownership of latrine & $0 / 1$ \\
\hline \multicolumn{4}{|l|}{ Consistent latrine use } \\
\hline \multicolumn{4}{|l|}{ Predictor variables } \\
\hline \multicolumn{4}{|l|}{ Risk Perception } \\
\hline Vulnerability & $\begin{array}{l}\text { How high or low are the chances that you contract } \\
\text { diarrheal disease when defecating in the open field? }\end{array}$ & $\begin{array}{l}\text { Five point scale, that ranges from almost } \\
\text { Very low, to Very high }\end{array}$ & 1 to 5 \\
\hline Severity & $\begin{array}{l}\text { If you have diarrheal disease because of open defecation, } \\
\text { how severely would that impact your life? }\end{array}$ & $\begin{array}{l}\text { Five point scale, that ranges from almost } \\
\text { Very low, to Very high }\end{array}$ & 1 to 5 \\
\hline \multicolumn{4}{|l|}{ Attitude (affective) } \\
\hline & $\begin{array}{l}\text { How much beneficial/important it is building Five point } \\
\text { scale, that ranges from almost Very low, to Very high } \\
\text { your own latrine in the one year }\end{array}$ & & 1 to 5 \\
\hline & $\begin{array}{l}\text { How much beneficial/important it is to defecate using } \\
\text { latrine regularly }\end{array}$ & $\begin{array}{l}\text { Five point scale, that ranges from almost } \\
\text { Very low, to Very high }\end{array}$ & 1 to 5 \\
\hline & How much do you like to use latrine? & $\begin{array}{l}\text { Five point scale, that ranges from almost } \\
\text { Very low, to Very high }\end{array}$ & 1 to 5 \\
\hline & How much do you do you enjoy defecating in latrine? & $\begin{array}{l}\text { Five point scale, that ranges from almost } \\
\text { Very low, to Very high }\end{array}$ & 1 to 5 \\
\hline \multirow{3}{*}{$\begin{array}{l}\text { Self-efficacy (latrine ownership) } \\
\text { Injective norm (latrine } \\
\text { ownership) }\end{array}$} & $\begin{array}{l}\text { How much ability you think you have building your } \\
\text { own latrine in the next one year }\end{array}$ & $\begin{array}{l}\text { Five point scale, that ranges from almost } \\
\text { Very low, to Very high }\end{array}$ & 1 to 5 \\
\hline & $\begin{array}{l}\text { Most of the people in my village think I should have } \\
\text { my own latrine }\end{array}$ & $\begin{array}{l}\text { Five point scale, that ranges from completely } \\
\text { disagree to completely agree }\end{array}$ & 1 to 5 \\
\hline & $\begin{array}{l}\text { People in my village will judge me if I don't have } \\
\text { my own }\end{array}$ & $\begin{array}{l}\text { Five point scale, that ranges from completely } \\
\text { disagree to completely agree }\end{array}$ & 1 to 5 \\
\hline \multirow[t]{3}{*}{ Descriptive norm (latrine use) } & $\begin{array}{l}\text { Most of the people I know in the community } \\
\text { defecate using latrine regularly }\end{array}$ & $\begin{array}{l}\text { Five point scale, that ranges from completely } \\
\text { disagree to completely agree }\end{array}$ & 1 to 5 \\
\hline & How many of your neighbors use latrine for defecation? & $\begin{array}{l}\text { Five point scale, that ranges from almost } \\
\text { nobody to almost all }\end{array}$ & 1 to 5 \\
\hline & $\begin{array}{l}\text { Using latrine regularly is the right thing to do because } \\
\text { everybody does so }\end{array}$ & $\begin{array}{l}\text { Five point scale, that ranges from completely } \\
\text { disagree to completely agree }\end{array}$ & 1 to 5 \\
\hline \multirow[t]{3}{*}{ Injunctive norm (latrine use) } & $\begin{array}{l}\text { people who are important to me approve /disapprove } \\
\text { that you use latrine }\end{array}$ & $\begin{array}{l}\text { Five point scale, that ranges from completely } \\
\text { disagree to completely agree }\end{array}$ & 1 to 5 \\
\hline & $\begin{array}{l}\text { Defecating using latrine is regularly is something that } \\
\text { most of the people in my village think }\end{array}$ & $\begin{array}{l}\text { Five point scale, that ranges from completely } \\
\text { disagree to completely agree }\end{array}$ & 1 to 5 \\
\hline & $\begin{array}{l}\text { People in my village will judge me if I defecate in the } \\
\text { open field }\end{array}$ & $\begin{array}{l}\text { Five point scale, that ranges from completely } \\
\text { disagree to completely agree }\end{array}$ & 1 to 5 \\
\hline \multicolumn{4}{|l|}{ Cues to action } \\
\hline \multicolumn{2}{|l|}{$\begin{array}{l}\text { Exposure to Health education } \\
\text { (HEW) }\end{array}$} & \multicolumn{2}{|l|}{ Yes/No } \\
\hline \multicolumn{2}{|l|}{ Exposure to CLTSH triggering } & \multicolumn{2}{|l|}{ Yes/No } \\
\hline
\end{tabular}

Items and scales used to measure the psychological factors for predicting latrine ownership and consistent latrine use

by asking three questions about the participants' feelings regarding latrine use. The composite score of the three items ranged from 4 to 15 , which was recorded as high attitude, for a score greater than 10, and low attitude, for a score 4 to 10 .

Perceived ability: (self-efficacy) The theory of planned behavior describes the individual's perception about their capacity to perform the desired behavior as self-efficacy.
Self-efficacy in the ability to build a latrine in the next 12 months was assessed for individuals who did not own a latrine using a Likert scale.

Cues to action: According to HBM, cues to action are strategies to activate the readiness of individuals, such as providing information, promote awareness, or reminders. Participants were asked about their participation in any sanitation promotion programs or their 
exposure to interpersonal and mass media communication on sanitation. Responses were recorded as reported by the participants.

Behavioral intent (intention): TRA/TPB propose that a person's intention when combined with perceived behavioral control will help predict behavior [38]. In this study, intention was defined as the behavioral intention to build a latrine in the coming year and was assessed only in those who did not own a latrine. The score, ranging from 1 to 5 , was recorded as high for the scores of 4 to 5 and low for the scores of 1 to 3 .

Latrine quality: Latrine quality was measured by observation and the subjective judgement of the data collectors. The cleanliness of a latrine was good if there was no sign of excrement anywhere and if the latrine was clean and tidy, fair when some excrement was found only around the pan/squatting plate, and poor when there was excrement on the floor or walls. Good and fair levels of cleanliness were categorized as clean, whereas poor cleanliness was recorded as unclean. We measured the variable 'Latrine has a protected entry door' as Yes when the door was made of a metal sheet, a sheet made of bamboo matting, wood, curved entrance with plastered walls, flat wood, and sheets made of bamboo, and No when there was no door or if there was a cloth curtain, curved entrance, unplastered wall, or plastic sack. The response for "Latrine has superstructure" was "Yes" when the wall was made of brick and cement, metal sheets, stone, stone/mud, sheets of bamboo matting, wood, etc., and the response was "No" when the wall was made of sesame stalk or leaves or if there was no wall.

\section{Data management and analysis}

Data were entered twice using the software Epi info version 3.5.4. Then, data screening and cleaning was performed by running frequencies and cross-tabulations. The clean data was exported to SPSS version 20 for analysis. The normal distribution assumption for the selected socio-demographic and main independent variables was analyzed using SPSS. Multicollinearity among independent variables was assed using the Shapiro-Wilk test. Descriptive summaries of the dependent variable, and all the potential predictor variables were obtained by running frequencies. Unadjusted logistic regression analyses were conducted to assess any significant association between each potential predicting factor and the outcome variable. Odds ratios with corresponding $95 \%$ confidence interval (CI) were used to quantify the degree of association. All variables having a $p$-value $\leq 0.05$ in the bivariate analysis were considered for multivariable logistic regression analysis. Since our study was limited to one time data collection, we were unable to explore the effect of intention and perceived ability on future behavior among non-owners of latrines. Rather, we presented the two variables as descriptive data.

\section{Results}

Background characteristics of the study participants

One thousand and forty-seven (1047) heads of household participated in the study with a response rate of $92 \%$. The demographic characteristics are summarized in Table 2. The mean age was 42 years, with a SD of 13.3. The majority were married (88.2\%), had no formal education $(58.2 \%)$ or primary education $(34.5 \%)$, were farmers (96.4\%), belonged to the Oromo ethnic group (99\%) and were followers of Orthodox Christian religion (99\%).

\section{Latrine ownership, past experience and future intention}

Among the study participants, 764 (73.0\%) owned latrine. The most common latrine type was unimproved traditional pit latrine $(98.5 \%)$. Of the 283 non-owners, $85 \%$ reported having high intention to build latrine within the coming year, but only $47 \%$ of latrine nonowners reported high perceived ability to do it. About

Table 2 Demographic characteristics of study participants in Becho district, Oromiya region of Ethiopia, May 2015 ( $n=1047)$

\begin{tabular}{|c|c|c|}
\hline Characteristics & $\begin{array}{l}\text { Number (\%) who } \\
\text { didn't own latrine }\end{array}$ & $\begin{array}{l}\text { Number (\%) } \\
\text { who own latrine }\end{array}$ \\
\hline \multicolumn{3}{|l|}{ Sex } \\
\hline Male & $166(58.7)$ & $484(63.4)$ \\
\hline Female & $117(41.3)$ & $280(36.6)$ \\
\hline \multicolumn{3}{|l|}{ Marital status } \\
\hline Married & $240(84.8)$ & $683(89.4)$ \\
\hline $\begin{array}{l}\text { Single/Divorced/widowed/ } \\
\text { separated }\end{array}$ & $43(15.2)$ & $81(10.6)$ \\
\hline \multicolumn{3}{|l|}{ Education Status } \\
\hline $\begin{array}{l}\text { No education/informal } \\
\text { education }\end{array}$ & $193(68.2)$ & $416(54.4)$ \\
\hline Primary education & $77(27.2)$ & $284(37.2)$ \\
\hline Secondary education and above & $13(4.6)$ & $64(8.4)$ \\
\hline \multicolumn{3}{|l|}{ Occupation } \\
\hline Farmer & $276(97.5)$ & $733(95.9)$ \\
\hline Others & $7(2.5)$ & $31(4.1)$ \\
\hline \multicolumn{3}{|l|}{ Age } \\
\hline$<31$ & $59(20.8)$ & $112(14.7)$ \\
\hline $31-50$ & $147(51.9)$ & $420(55)$ \\
\hline $50+$ & $77(27.2)$ & $232(30.4)$ \\
\hline \multicolumn{3}{|l|}{ Family size } \\
\hline $1-6$ & $205(72.4)$ & $455(59.6)$ \\
\hline $7-10$ & $74(26.1)$ & $271(35.5)$ \\
\hline $10+$ & $4(1.4)$ & $38(5.0)$ \\
\hline
\end{tabular}


98.6\% of latrine non-owners had latrine in previous years and there was some kind of convincing evidence of this for $75.3 \%$ of non-owners. The listed reasons for ceasing to use latrine were because latrine had collapsed (62\%), or latrine was full (28\%).

\section{Latrine use}

Six hundred three (79\%) participants reported to consistently use latrines. The proportion of participants that reported "very often", "less often" or "never" used latrine during the past one week was 132 (17.3\%), 11(1.4\%), and $19(2.5 \%)$ respectively.

\section{The individual psychological factors}

The mean, range, and standard for each individual psychological item are summarized in Table 3. The mean (standard deviation) of composite scores were 8.0 (1.8) for injunctive norm of latrine ownership, 10.4(2.3) for injective norm of latrine use, 10.4 (2.3) for descriptive norm (latrine use), 3.5 (1.3) for perceived ability, 13.6 (1.8) for attitude, 4.6 (0.8) for perceived vulnerability, and $4.5(0.8)$ for perceived severity respectively.

\section{Exposure to communication about sanitation (cues to action)}

The majority of participants $(93.7 \%)$ reported that they were advised or motivated by someone to build a latrine; almost all (98.2\%) were advised by the government health extension workers; $21 \%$ of the respondents reported that their family member took part in CLTSH triggering events during the previous year.

\section{Psychological predictors of latrine ownership}

Results of the logistic regression showing the crude and adjusted effects of four psychological factors, demographic factors, and cues to action on the odds of latrine ownership are summarized in Table 4. In a univariate analysis, latrine ownership was positively and significantly associated with perceived severity (OR 2.71; $95 \%$ CI 1.78-4.15), attitude (OR 2.05; 95\% CI 1.55-2.71) and injunctive norm (OR 7.71; 95\% CI 1.77-4.15). In the multiple logistic regression analysis that considered selected demographic factors, cues to action, and the psychological factor (i.e., perceived vulnerability, perceived severity, attitude, descriptive norm and injunctive norm), showed that $77.6 \%$ of the study participants were correctly classified, and $21.7 \%$ (Cox and Snell R-square) to $31.4 \%$ (Nagelkerke R-square) of the total variability in the outcome was explained by the model ( $p$-value < 0.05 ), and two psychological factors, namely, attitude (AOR 1.70; 95\% CI 1.21-2.37) and injunctive norm (AOR 6.18; 95\% CI 4.46-10.44)-were positively and significantly associated with latrine ownership. Among the demographic factors, those with a family size of more than 6 compared to small-sized families $(\mathrm{AOR}=1.43$; 95\% CI 1.01-1.97) were more likely to be latrine owners, as were households with a child attending school, compared to those who did not have $(\mathrm{AOR}=1.88 ; 95 \% \mathrm{CI}$ 1.17-3.02), and the head of household having high school education (AOR $=1.98$; 95\% CI: 1.34-2.87). With respect to exposure to communication about sanitation (cues to action), households with a family member who took part in CLTSH triggering were 3 times more likely to be latrine owners than those who did not participate in CLTSH triggering (95\% CI 1.92-4.78).

\section{Predictors of consistent latrine use}

Results from logistic regression analysis of consistent latrine use as an outcome variable, and demographic, psychological, and latrine quality factors as predictor variables are displayed in Table 5. The univariate regression analysis of each psychological factor (i.e. perceived vulnerability, perceived severity, attitude, descriptive norm and injunctive norm), and consistent latrine use showed that attitude (OR $=6.48$; 95\% CI 4.44-9.45), perceived vulnerability $(\mathrm{OR}=2.17,95 \% \mathrm{CI} 1.50-3.14)$, perceived severity $(\mathrm{OR}=2.71 ; 95 \%$ CI $1.77-4.15)$, and injective norm $(\mathrm{OR}=1.34,95 \% \mathrm{CI} 1.00-1.90)$ were significantly associated with consistent latrine use $(\mathrm{OR}=$ 7.45; 95\% CI 4.91-11.30). In the multivariate logistic regression, $78.8 \%$ of the study participants were correctly classified, and the model explained between 18.2\% (Cox

Table 3 Descriptive statistics of the psychological predictors of latrine ownership and consistent latrine use $(n=1047)$

\begin{tabular}{|c|c|c|c|c|}
\hline Psychological factors & Range (Min, Max) & Mean & SD & Number of Items \\
\hline \multicolumn{5}{|l|}{ Risk Perception } \\
\hline Vulnerability & $4(1,5)$ & 4.33 & 0.79 & 1 \\
\hline Severity & $4(1,5)$ & 4.48 & 0.75 & 1 \\
\hline Attitude & $11(4,15)$ & 13.63 & 1.75 & 4 \\
\hline Injunctive norm (latrine ownership) & $8(2,10)$ & .8 .0 & 1.79 & 2 \\
\hline Self-efficacy (latrine ownership) & $4(1,5)$ & 3.45 & 1.29 & 1 \\
\hline Descriptive norm (consistent latrine use) & $11(4,15)$ & 10.37 & 2.32 & 3 \\
\hline Injective norm (consistent latrine use) & $11(3,15)$ & 10.37 & 2.31 & 3 \\
\hline
\end{tabular}


Table 4 Results from logistic regression assessing predictors of latrine ownership in Becho district. May $2015(n=1047)$

\begin{tabular}{|c|c|c|c|c|}
\hline Characteristics & Number (\%) who didn't own latrine & Number (\%) who own latrine & COR(95\%Cl) & $\mathrm{AOR}(95 \% \mathrm{Cl})$ \\
\hline \multicolumn{5}{|l|}{ 1.Psychological factors } \\
\hline \multicolumn{5}{|l|}{ Perceived vulnerability } \\
\hline Low & $58(20.5)$ & $81(10.6)$ & 1.00 & 1.00 \\
\hline High & $225(79.5)$ & $683(89.4)$ & $1.15(0.57-2.32)$ & $1.15(0.57-2.32)$ \\
\hline \multicolumn{5}{|l|}{ Perceived severity } \\
\hline Low & $46(16.3)$ & $51(6.7)$ & 1.00 & 1.00 \\
\hline High & $237(83.7)$ & $713(93.3)$ & $2.71(1.77-4.15)$ & $1.15(0.57-2.32)$ \\
\hline \multicolumn{5}{|l|}{ Attitude } \\
\hline Low & $151(53.4)$ & $250(32.7)$ & 1.00 & 1.00 \\
\hline High & $132(46.4)$ & $514(67.3)$ & $2.05(1.55-2.71)$ & $1.70(1.21-2.37)^{*}$ \\
\hline \multicolumn{5}{|l|}{ Injunctive norm (latrine ownership) } \\
\hline Low & $188(66.4)$ & $316(41.6)$ & 1.00 & 1.00 \\
\hline High & 95 (33.6) & $444(58.4)$ & $7.71(5.70-4.60)$ & $6.18(4.46-10.44)^{*}$ \\
\hline \multicolumn{5}{|l|}{ 2.Cues to action } \\
\hline \multicolumn{5}{|l|}{ Advised by Health extension worker } \\
\hline No & $17(6.0)$ & $67(8.8)$ & 1.00 & 1.0 \\
\hline Yes & $266(94.0)$ & $697(91.2)$ & $0.67(0.38-1.15)$ & $0.78(0.41-1.46)$ \\
\hline \multicolumn{5}{|c|}{ Family members participated in CLTSH triggering } \\
\hline No & $256(90.5)$ & $569(74.5)$ & 1.00 & 1.00 \\
\hline Yes & $27(9.5)$ & $195(25.5)$ & $3.25(2.12-4.50)$ & $3.02(1.88-4.84)^{*}$ \\
\hline \multicolumn{5}{|l|}{ 3.Socio-demographic variables } \\
\hline \multicolumn{5}{|l|}{ Age group } \\
\hline$<30$ & $59(20.8)$ & $112(14.7)$ & 1.00 & 1.00 \\
\hline $30-49$ & $147(51.9)$ & $420(55.0)$ & $1.51(1.04-2.17)$ & $1.33(0.87-2.03)$ \\
\hline $50+$ & $77(27.2)$ & $232(30.3)$ & $1.58(1.05-2.38)$ & $1.66(0.99-2.80)$ \\
\hline \multicolumn{5}{|l|}{ Marital status } \\
\hline \multicolumn{5}{|l|}{ Single/divorced/widowed } \\
\hline Separated & $43(15.2)$ & $81(10.6)$ & 1.00 & 1.00 \\
\hline Married & $240(84.8)$ & $683(89.4)$ & $1.51(1.02-2.24)$ & $1.43(0.89-2.28)$ \\
\hline \multicolumn{5}{|l|}{ Education Status } \\
\hline No education/informal Education & $193(68.2)$ & $416(54.4)$ & 1.00 & 1.00 \\
\hline Primary education(grade 1-8) & $77(27.2)$ & $284(37.2)$ & $1.71(1.26-2.32)$ & $1.89(0.93-3.87)$ \\
\hline High school and college & $13(4.6)$ & $64(8.4)$ & $2.28(1.23-4.25)$ & $1.98(1.36-2.87)^{*}$ \\
\hline \multicolumn{5}{|l|}{ Family size } \\
\hline$<=6$ & $205(72.4)$ & $455(59.6)$ & 1.00 & 1.00 \\
\hline$>6$ & 78 (27.6) & $309(40.4)$ & $1.81(1.35-2.44)$ & $1.41(1.01-1.97)^{*}$ \\
\hline \multicolumn{5}{|l|}{ Presence of a school child } \\
\hline No & $53(18.7)$ & $82(10.7)$ & 1.00 & 1.00 \\
\hline Yes & $230(81.3)$ & $682(89.3)$ & $1.91(1.31-2.79)$ & $1.97(1.27-3.06)^{*}$ \\
\hline
\end{tabular}

*Significant at $P<0.05$

and Snell R-square) and 28.3\% (Nagelkerke R-square) of the total variability ( $p$-value <0.05). The results show that three factors related to latrine quality, that were a clean latrine $(\mathrm{OR}=1.69 ; 95 \% \mathrm{CI} 1.00-3.00)$, a latrine with protected door $(\mathrm{OR}=1.94$; $95 \%$ CI 1.10 $3.48)$, and a latrine with a superstructure $(\mathrm{OR}=2.26$; CI 1.47-3.48) had a significant positive association with consistent latrine use. Factors not associated 
Table 5 Results from logistics regression assessing the association between potential predictors and consistent latrine use in Becho district of Ethiopia. May 2015. $(n=764)$

\begin{tabular}{|c|c|c|c|c|}
\hline Characteristics & $\begin{array}{l}\text { Number (\%) who did not } \\
\text { consistently used latrine }\end{array}$ & $\begin{array}{l}\text { Number (\%) who consistently } \\
\text { used latrine }\end{array}$ & $\operatorname{COR}(95 \% \mathrm{Cl})$ & $\mathrm{AOR}(95 \% \mathrm{Cl})$ \\
\hline \multicolumn{5}{|l|}{ Psychological factors } \\
\hline \multicolumn{5}{|l|}{ Perceived vulnerability } \\
\hline Low & $24(14.78)$ & $57(9.5)$ & 1.00 & 1.00 \\
\hline High & $138(85.2)$ & $545(90.5)$ & $2.17(1.50-3.14$ & $2.069(0.97-4.41)$ \\
\hline \multicolumn{5}{|l|}{ Perceived severity } \\
\hline Low & $11(6.8)$ & $40(6.6)$ & 1.00 & 1.00 \\
\hline High & $151(93.2)$ & $562(93.4)$ & $2.71(1.77-4.15)$ & $0.30(0.11-0.80)$ \\
\hline \multicolumn{5}{|l|}{ Attitude } \\
\hline Low & $108(66.7)$ & $142(23.6)$ & 1.00 & 1.00 \\
\hline High & $54(33.3)$ & $460(76.4)$ & $6.48(4.44-9.45)$ & $7.45(4.91-11.30)$ \\
\hline \multicolumn{5}{|c|}{ Descriptive norm (latrine use) } \\
\hline High & $71(43.8)$ & $257(42.8)$ & 1.00 & 1.00 \\
\hline Low & $91(56.2)$ & $343(57.2)$ & $1.04(0.73-1.48)$ & $0.95(0.63-1.44)$ \\
\hline \multicolumn{5}{|l|}{ Injunctive norm (latrine use) } \\
\hline Low & $184(65.0)$ & $405(53.0)$ & 1.00 & 1.00 \\
\hline High & $99(35)$ & $359(47.0)$ & $1.34(1.00-1.90)$ & $1.23(0.80-1.90)$ \\
\hline \multicolumn{5}{|l|}{ Demographic variables } \\
\hline \multicolumn{5}{|l|}{ Age group } \\
\hline$<30$ & $22(13.6)$ & $90(15.0)$ & 1.00 & 1.00 \\
\hline $30-49$ & $92(58.6)$ & $328(54.5)$ & $0.87(0.52-1.47)$ & $0.79(0.43-1.45)$ \\
\hline $50+$ & $48(29.6)$ & $184(30.5)$ & $0.94(0.53-1.65)$ & $0.71(0.35-1.40)$ \\
\hline \multicolumn{5}{|l|}{ Education Status } \\
\hline No/informal education & $84(52.0)$ & $332(55.0)$ & 1.00 & 1.00 \\
\hline Primary Education & $69(42.6)$ & $215(5.7)$ & $0.79(0.55-1.13)$ & $0.66(0.42-1.05)$ \\
\hline Secondary education & $9(5.6)$ & $15(9.0)$ & $1.54(0.74-3.30)$ & $0.86(0.36-2.04)$ \\
\hline \multicolumn{5}{|l|}{ School child present } \\
\hline No & $17(10.5)$ & $65(10.8)$ & 1.00 & 1.00 \\
\hline Yes & $145(89.5)$ & $537(89.2)$ & $0.97(0.55-1.70)$ & $0.90(0.46-1.73)$ \\
\hline \multicolumn{5}{|l|}{ Family size } \\
\hline $0-6$ & $97(60.6)$ & $351(58.8)$ & 1.00 & 1.00 \\
\hline$>6$ & $63(39.4)$ & $246(41.2)$ & $1.08(0.76-1.54)$ & $1.06(0.71-1.59)$ \\
\hline \multicolumn{5}{|l|}{ Gender } \\
\hline Male & $103(63.6)$ & $381(63.0)$ & 1.00 & 1.00 \\
\hline Female & $59(36.4)$ & $221(37.0)$ & $1.01(0.71-1.45)$ & $1.05(0.67-1.66)$ \\
\hline \multicolumn{5}{|l|}{ Exposure to communication } \\
\hline \multicolumn{5}{|l|}{ Advised by HEW } \\
\hline No & $20(12.3)$ & $47(7.8)$ & 1.00 & 1.00 \\
\hline Yes & $142(87.7)$ & $555(92.2)$ & $1.66(0.95-2.90)$ & $0.60(0.35-1.05)$ \\
\hline \multicolumn{5}{|l|}{ Participated in CLTSH } \\
\hline No & $119(73.5)$ & $450(74.8)$ & 1.00 & 1.00 \\
\hline Yes & $43(26.5)$ & $152(25.2)$ & $0.94(0.63-1.39)$ & $1.02(0.64-1.62)$ \\
\hline
\end{tabular}


Table 5 Results from logistics regression assessing the association between potential predictors and consistent latrine use in Becho district of Ethiopia. May 2015. ( $n=764)$ (Continued)

\begin{tabular}{|c|c|c|c|c|}
\hline Characteristics & $\begin{array}{l}\text { Number (\%) who did not } \\
\text { consistently used latrine }\end{array}$ & $\begin{array}{l}\text { Number (\%) who consistently } \\
\text { used latrine }\end{array}$ & $\operatorname{COR}(95 \% \mathrm{Cl})$ & AOR(95\%Cl) \\
\hline \multicolumn{5}{|c|}{ Latrine quality factors } \\
\hline \multicolumn{5}{|l|}{ Clean latrine } \\
\hline No & $38(23.5)$ & $60(10.0)$ & 1.00 & 1.00 \\
\hline Yes & $124(75.5)$ & $542(90.0)$ & $2.77(1.76-4.35)$ & $1.69(1.00-3.00)$ \\
\hline \multicolumn{5}{|c|}{ Latrine has protected entry } \\
\hline No & $144(89)$ & $454(75.4)$ & 1.00 & 1.00 \\
\hline Yes & $18(11)$ & $148(24.6)$ & $2.61(1.54-4.40)$ & $1.94(1.10-3.48)$ \\
\hline \multicolumn{5}{|c|}{ Latrine has superstructure } \\
\hline No & $96(59.3)$ & $222(37)$ & 1.00 & 1.00 \\
\hline Yes & $66(40.7)$ & $380(63.0)$ & $2.48(1.74-3.54) *$ & $2.26(1.47-3.48)^{*}$ \\
\hline
\end{tabular}

with consistent latrine use in the univariate logistic regression were cues to action (being advised by a health extension worker or participating in CLTSH triggering) and demographic variables, such as age, gender, family size, education status, and the presence of a child who attended school.

When factors that showed significant association in the univariate logistic regression analysis were entered for multivariate logistic regression analysis, one of the psychological factors (attitude) and the three latrinequality factors remained significant. Participants who had a positive attitude toward latrines were 7 times more likely to be consistent latrine users (95\% CI 4.91-11.30). Participants who owned a clean latrine were 1.69 times more likely to be consistent latrine users compared to those who owned dirty latrines (95\% CI 1.00-3.00). Latrines that had a superstructure were 2.3 times more likely to be used consistently compared with latrines that did not have a superstructure (95\% CI 1.47-3.48). Latrines that had a protected door were 1.94 times more likely to be consistently used than were latrines with no door (95\% CI 1.10-3.48).

\section{Discussion}

This cross-sectional quantitative study sought to identify the psychological predictors of latrine ownership in the rural Becho district of Ethiopia. The study found that $73 \%$ of participants owned a latrine, and consistent latrine use among latrine owners was 79\%. Among the psychological factors, attitude and norm perception predicted latrine ownership. Having a larger family size, the head of household having a higher level of education, having a child attending school, and having a family member who participated in CLTSH triggering were significantly associated with latrine ownership. The findings demonstrated that having a positive attitude toward latrine, owning a clean latrine, owning a latrine with a protected door and a latrine with a superstructure had a significant positive association with consistent latrine use.

The ownership of any kind of latrine by $73 \%$ of the participants in this study shows improvement in the country compared with the level of latrine coverage reported by studies in the past decade. Various levels of latrine utilization with some level of geographical variations were reported in previous Ethiopia studies: 61\% in rural Hulet Ejju Enessie Woreda [45]; 62\% in Bahir Dar Zuria [46], and 45-50\% in Hawzen district [47]. However, only $1.5 \%$ having access to an improved latrine shows that access to an improved sanitation remains far below any of the targets [18, 48, 49] which needs urgent attention. This finding was close to the $4 \%$ access to improved latrines in rural Ethiopia reported by the 2016 Ethiopia DHS report [13, 45, 46] and the WHO and UNICEF JMP reports [6].

This study found that attitude and the injunctive norm were the predictors of latrine ownership, which showed that the social norm influenced people's decision to own a latrine [40]. Consistent with this finding, a study in Zambia reported that open defecation was commonly practiced because of its acceptance as a societal norm [50]. Given this finding, we believe that normative and persuasive intervention is appropriate for the current setting $[27,51]$. CLTSH is a behavior change approach that uses normative and shocking techniques in rural sanitation interventions [51, 52].This study also found that participation in the CLTSH triggering has a significant positive associated with latrine ownership. The current study was conducted in rural Becho, which is a typical rural setting in Ethiopia. We believe that the suggestion of a normative and persuasive approach can be generalized for most of the rural Ethiopia, where $85 \%$ of the population resides. However, the generalizability may be limited in some contexts because of the ethnic 
diversity of A high level of intention to build a latrine in the coming year was reported by the majority of nonadopter household participants. Other studies reported a lower intention to install latrines. For example, a study conducted in Ghana reported a 30\% intention level among those who did not own a latrine [53]. However, in this study, given that almost half of intenders reported having low perceived ability (self-efficacy), there was a smaller chance that their intention could be executed [44]. The large majority of non-owners reported having a latrine in the past, and the reason for stopping use of the latrine was because it had collapsed or was broken. This highlighted that latrine ownership might not be sustained. It might be possible that other non-behavioral contextual factors influenced the adoption of a latrine [25]. We recommend further research to explore this.

This study found that attitude was the most powerful predictor of consistent latrine use. The results of this study also showed that cleanliness was associated with consistent latrine use. Consistent with these findings, studies in Ethiopia and other countries also reported that unclean and poorly maintained latrines created a negative perception about latrines and discouraged people from using them [54-56]. The study results show that latrines with a door and latrines with a superstructure were more likely to be consistently used, which might be related to privacy.

The findings from this study show that access to an improved latrine was very limited. This study also highlighted that non-owners have a high intention to install a latrine. Converting this high intention to action (latrine adoption) and sustaining adopted latrines were identified as challenges in the study area. The study also revealed that the socio-demographic status of participants, such as having a better educational status, having a child attending school, and a larger family size influenced latrine ownership. This study found that factors related to latrine quality were significantly associated with consistent latrine use, and among psychological factors, only attitude has a significant association with consistent latrine use. Therefore, efforts to increase latrine adoption should be based on the understanding of multidimensional influences. Investigating the effectiveness of a normative and persuasive approach to health education is suggested for future research. Before generalizing the findings of this study, one should consider that the study was conducted in a very homogenous population, in which $96.4 \%$ were farmers, 99\% belonged to the Oromo ethnic group, and 99\% were followers of Orthodox Christian religion.

\section{Strength and limitations}

- Using a standardized Likert scale adapted from theoretical behavioral models, this study measured the psychological predictors of latrine ownership and consistent latrine use, which was a constraint in previous studies.

- We involved a large sample size and collected preliminary background information using focus group discussion (FGD) as an input for designing the questionnaire, which was the strength of this study.

- We failed to establish causal relationships between potential predictors and the outcome under investigation because our findings were based on a cross-sectional study design.

- We were unable to show the effect of descriptive norm on latrine ownership.

\section{Conclusion}

The study findings show that attitude about latrines and social norms were the psychological predictors of latrine ownership, and consistent latrine use was associated with attitude, the cleanliness of latrine and its privacy. Hence, sanitation intervention needs to focus on changing societal norms and attitudes and maintaining latrine quality.

\section{Abbreviations \\ AOR: Adjusted Odds Ratio; CLTSH: Community Led Total Sanitation and Hygien.; DHS: Demographic Health Survey; FMOH: Federal Ministry of Health; OR: Odds Ratio; RANAS: Risk, Attitude, Norm, Ability, Self-regulation; \\ SPSS: Statistical Package for the Social Sciences; TPB: Theory of Planned Behavior; TRA: Theory of Reasoned Action; TSNB: Theory of Social Norm Behavior; UNICEF: United Nations International Children's Emergency Fund; WASH: Water, Sanitation and Hygiene}

\section{Acknowledgements}

This study would not have been successful without the voluntary participation of study participants and data collectors. We also would like to acknowledge the support of Becho woreda health office during data collection.

\section{Funding}

Funding for data collection was obtained from Addis Ababa University, Ethiopian Institute of Water Resources.

\section{Availability of data and materials}

All the necessary data and materials were analyzed and included in this manuscript. For further need, data can be obtained from the primary author upon request.

\section{Authors' contributions}

FA led the study design, analysis and write-up of the manuscript. AK has participated in the review and guidance of the design, analysis, and manuscript write-up. GM has participated in guiding the analysis and manuscript drafting. JG has participated in manuscript write up. All authors read and approved the final manuscript.

\section{Authors' information}

FA, PhD fellow at Addis Ababa University, Institute Of Water Resources, Water and Health Program, is a lead investigator of the study. AK, PhD, Public Health Expert, Addis Ababa University, is a lead supervisor, JG, Associate Professor in Environmental \& Occupational Health, Kuwait University, is a collaborator. GM, PhD in Epidemiology, Addis Ababa University, is collaborator. 


\section{Ethics approval and consent to participate}

Ethical clearance was obtained from the Ethical Review Committee of Oromia Regional Health Bureau. Written informed consent was obtained from the study participants and included consent to participate and to publish the findings. Interviews were conducted in the privacy of the participants' houses. All data forms were stored in a confidential and secured place.

\section{Consent for publication}

\section{Not applicable.}

\section{Competing interests}

The authors declare that they have no competing interests.

\section{Publisher's Note}

Springer Nature remains neutral with regard to jurisdictional claims in published maps and institutional affiliations.

\section{Author details}

${ }^{1}$ Ethiopian Institute of Water Resources, Water and Health Program, Addis Ababa University, Addis Ababa, Ethiopia. ${ }^{2}$ School of Public Health, College of Health Sciences, Addis Ababa University, Addis Ababa, Ethiopia. ${ }^{3}$ Aklilu Lemma Institute of Pathobiology, Addis Ababa University, Addis Ababa, Ethiopia. ${ }^{4}$ Kuwait University, Faculty of Public Health, Department of Environmental \& Occupational Health, Safat 13110, Kuwait, Kuwait.

\section{Received: 8 June 2017 Accepted: 1 February 2018} Published online: 08 February 2018

\section{References}

1. Clasen T, Bostoen K, Schmidt W, Boisson S, Fung I, Jenkins M, Scott B, Sugden S, Cairncross S: Interventions to improve disposal of human excreta for preventing diarrhoea. International journal of Epidemology 2010, Supplement 1(39):i193-i205.

2. Waddington $\mathrm{H}$, Snilstveit B. Effectiveness and sustainability of water, sanitation, and hygiene interventions in combating diarrhoea. Journal of development effectiveness. 2009;1(3):295-335.

3. Barreto M, Genser B, Strina A, Assis A, Rego R, Teles C, Prado M, Matos S, Santos D, Santos L, et al. Effect of city-wide sanitation programme on reduction in rate of childhood diarrhoea in northeast Brazil: assessment by two cohort studies. Lancet. 2007;370(9599):1622-8.

4. Brown J, Cairncross S, Ensink J. Water, sanitation, hygiene and enteric infections in children. Arch Dis Child. 2013:98(8):629-34.

5. Prüss-Ustün A, Bartram J, Clasen T, Colford JC, Cumming O, Curtis V, Bonjour $S$, Dangour A, France J, Fewtrell $L$, et al. Burden of disease from inadequate water, sanitation and hygiene in low and middle income settings: a retrospective analysis of data from 145 countries. Tropical Med Int Health. 2014;19(8):894-905.

6. WHO, UNICEF: Progress on drinking water, sanitation and hygiene: 2017 update and SDG baselines; 2017.

7. WHO: Global health risks: mortality and burden of disease attributable to selected major risks: World Health Organization; 2009.

8. Black R, Cousens S, Johnson H, Lawn J, Rudan I, Bassani D, Jha P, Campbell $\mathrm{H}$, Walker C, Cibulskis R, et al. Global, regional, and national causes of child mortality in 2008: a systematic analysis. Lancet. 2010;375(9730):1969; 1987.

9. Tessa W, Peter S, Clarissa B, Mickey C, Elizabeth M. Diarrhoea: why children are still dying and what can be done. Lancet. 2010;375(9718):870; 872.

10. Hotez PJ, Kamath A. Neglected tropical diseases in sub-Saharan Africa: review of their prevalence, distribution, and disease burden. PLoS Negl Trop Dis. 2009;3(8):e412

11. Mathers C, Fat D, Boerma J. The global burden of disease: 2004 update. Geneva, Switzerland: world health. Organization. 2008;

12. Deribe K, Meribu K, Gebre T, Hailu A, Ali A, Assefa A, Davey G. The burden of neglected tropical diseases in Ethiopia, and opportunities for integrated control and elimination. Parasites and Vectors. 2012:5(240):1; 15

13. CSA: Ethiopia Demographic and Health Survey 2016 Report. Addis Ababa, Ethiopia, and Rockville, Maryland, USA: SA and ICF; 2017.

14. UNICEF sanitation priority country factsheet [http://www.unicef.org/ ethiopia/Ethiopia_Fact_Sheet_Jan_2014. final.pdf].

15. FMOH: Ethiopian National Hygiene \& Sanitation Strategic Action Plan for Rural, Peri-Urban \& Informal Settlements 2011-2015. Addis Ababa; 2011.

16. $\mathrm{FMOH}$ : Ethiopian national sanitation marketing guideline. Addis Ababa; 2013.
17. FMOH. Ethiopian health sector transformation plan (HSTP) 2015/2016-2019/ 2020. Federal Ministry of Health: Addis Ababa; 2015.

18. FDRE. National Hygiene \& Sanitation Strategic Action Plan for rural. Addis Ababa: Per-Urban \& Informal Settlements in Ethiopia Part II. Edited by Health $\mathrm{FMOH} ; 2011$.

19. WHO: Progress on Water Drinking Water and Sanitation-2015 update. Geneva: World Health Organization; 2015.

20. Cairncross $S$, Shordt K. It does last! Some findings from a multi-country study of hygiene sustainability. Waterlines. 2004;22(3):4-7.

21. Mara D, Lane J, Scott B, Trouba D. Sanitation and health. PLoS Med. 2010;7(11)

22. Peal A, Evans B, van der Voorden C. Hygiene and sanitation software: an overview of approaches. Switherland: water supply and sanitation. Program. 2010;

23. Merchant AT, Jones C, Kiure A, Kupka R, Fitzmaurice G, Herrera MG, Fawzi WW. Water and sanitation associated with improved child growth. European journal of clinical nutrition. Eur J Clin Nutr. 2003;57(12):1562-8.

24. Glanz K, Bishop DB. The role of behavioral science theory in development and implementation of public health interventions. Annu Rev Public Health. 2010;31(1):399-418.

25. Dreibelbis R, Winch PJ, Leontsini E, Hulland K, Ram PK, Unicomb L, Luby SP. The Integrated Behavioral Model for Water, Sanitation, and Hygiene: a systematic review of behavioral models and a framework for designing and evaluating behavior change interventions in infrastructure-restricted settings. BMC Public Health. 2013;13(1015):1; 13

26. Noar SM, Zimmerman RS. Health behavior theory and cumulative knowledge regarding health behaviors: are we moving in the right direction? Health Educ Res. 2005;20(3):275-90

27. Mosler H-J. A systematic approach to behavior change interventions for the water and sanitation sector in developing countries: a conceptual model, a review, and a guideline. Int J Environ Health Res. 2012:22:431-49.

28. Connell K: What influences open defecation and latrine ownership in rural households?: findings from global review. 2014.

29. MOH: Becho Woreda Health Report. Becho; 2015.

30. CSA: Federal Democratic Republic of Ethiopia. Summary and Statistical Report of the 2007 Addis Ababa: Population Census Commission; 2008.

31. CSA: Ethiopia mini demographic health survey. Addis Ababa: Central Statistics Agency; 2014.

32. Redding C, Rossi J, Rossi S, Velicer W, Prochaska J: Health Behavior Models. Journal of Health Education 2000, Special Issue: 180; 193.

33. Lapinski MK, Anderson J, Shugart A, Todd E. Social influence in child care centers: a test of the theory of normative social behavior. Health Commun. 29(3):219-32.

34. Mullan B, Wong C. Using the Theory of Planned Behaviour to design a food hygiene intervention. Food Control. 21(11):1524-9.

35. Trafimow D, Sheeran P. Some tests of the distinction between cognitive and affective beliefs. J Exp Soc Psychol. 1998;34(4):378-97.

36. Inauen J, Hossain MM, Johnston RB, Mosler H-J: Acceptance and use of eight arsenic-safe drinking water options in Bangladesh: Bibliothek der UniversitÃat Konstanz.

37. Graf J, Meierhofer R, Wegelin M, Mosler HJ. Water disinfection and hygiene behavior in an urban slum in Kenya: impact on childhood diarrhoea and influence of beliefs. International Journal of Environmental Health Research. 2008:18(5):335; 355.

38. Ajzen I. Constructing a theory of planned behavior questioner. In Brief Description of the Theory of Planned Behavior. 2006;1:7.

39. Ajzen I, Fischbein M: Understanding attitudes and predicting social behavior Englewood cliffs; 1980.

40. Lapinski M, Rimal R. An explication of social norms. Communication Theory. 2005:152(2):127-47.

41. Rimal RN, Real K. How behaviors are influenced by perceived norms a test of the theory of normative social behavior. Commun Res. 2005;32(3):389-414.

42. Klöckner CA, Matthies E. How habits interfere with norm-directed behaviour: a normative decision-making model for travel mode choice. J Environ Psychol. 2004;24(3):319-27.

43. Rimal RN. Modeling the relationship between descriptive norms and behaviors: a test and extension of the theory of normative social behavior (TNSB). Health Commun. 2008;23:104-16.

44. Ajzen I. The theory of planned behavior. Organ Behav Hum Decis Process. 1991;50(2):179-211.

45. Anteneh A, Kumie A. Assessment of the impact of latrine utilization on diarrheal diseases in the rural community of Hulet Ejju Enessie Woreda, East 
Gojam Zone, Amhara Region. Ethiopian Journal of Helath Development. 2010;24(2):111; 117.

46. Awoke W, Muche S. A cross sectional study: latrine coverage and associated factors among rural communities in the District of Bahir Dar Zuria, Ethiopia. BMC Public Health. 2013;13(99):1; 6.

47. Ashebir Y, Rai Sharma H, Alemu K, Kebede G. Latrine use among rural households in northern Ethiopia: a case study in Hawzien district, Tigray. Int J Environ Stud. 2013;70(4):629-36.

48. WHO, UNICEF: Meeting the MDG drinking water and sanitation target: the urban and rural challenge of the decade; 2006.

49. FMOH. National Hyegine and sanitation strategy. Addis Ababa: Federal Democratic Republic of Ethiopia Ministry of Health; 2005.

50. Thys S, Mwape KE, Lefèvre P, Dorny P, Marcotty T, Phiri AM, Phiri IK, Gabriël S. Why latrines are not used: communities' perceptions and practices regarding latrines in a Taenia solium endemic rural area in eastern Zambia. PLoS Negl Trop Dis. 2015 Mar 4;9(3):e0003570.

51. Sah S, Negussie A. Community led total sanitation (CLTS): addressing the challenges of scale and sustainability in rural Africa. Desalination. 2009; 248(1):666-72

52. Engel S, Susilo S. Shaming and sanitation in Indonesia: a return to colonial public health practices? Dev Chang. 2014;45(1):157; 178.

53. Jenkins MW, Scott B. Behavioral indicators of household decision-making and demand for sanitation and potential gains from social marketing in Ghana. Journal of Social Science and Medcine. 2007;64(12):2427-42.

54. Yimam YT, Gelaye KA, Chercos DH. Latrine utilization and associated factors among people living in rural areas of Denbia district, Northwest Ethiopia, 2013, a cross-sectional study. The Pan African medical journal. 2013;18

55. Rheinländer T, Keraita B, H S, Dalsgaa A: Smell: an overlooked factor in sanitation promotion. Waterlines 2013, 32(2).

56. Lundblad B, Hellstrom AL. Perceptions of school toilets as a cause for irregular toilet habits among schoolchildren aged 6 to 16 years. J Sch Health. 2005;75(4):125-8.

\section{Submit your next manuscript to BioMed Central and we will help you at every step:}

- We accept pre-submission inquiries

- Our selector tool helps you to find the most relevant journal

- We provide round the clock customer support

- Convenient online submission

- Thorough peer review

- Inclusion in PubMed and all major indexing services

- Maximum visibility for your research

Submit your manuscript at www.biomedcentral.com/submit

) Biomed Central 